\title{
Эмпирический подход к иерархической теории структуры капитала
}

\author{
Луценко С.И. ${ }^{12}$
}

В данной статье на примере публичных американских компаний анализируется верификация иерархической теории структуры капитала (pecking order theory). Проводится тест иерархической теории с использованием прокси-переменной (ргоху) - финансового дефиџита. Финансовый дефицит является наименее важной переменной в объяснении чистой эмиссии долга для различных по величине компаний.

JEL: G32

Ключевые слова: структура капитала, теория порядка финансирования, дефицит финансирования

Иерархическая теория структуры капитала является одной из самых влиятельных теорий корпоративного левереджа. По словам Майерса [Myers, 1984], из-за проблемы неблагоприятного отбора компании предпочитают внутреннее финансирование внешнему. Когда внешнее финансирование является необходимым, компании предпочитают выпускать долг, нежели проводить эмиссию ценных бумаг, потому что информационные затраты, связанные с эмиссией долга, являются ниже, чем затраты, связанные с эмиссией акций. Компании редко прибегают к выпуску собственного капитала. Данное утверждение было проверено с помощью эмпирических свидетельств Шиам-Сандера и Майеpса [Shyam-Sunder, Myers, 1999]. Дефицит финансирования должен соответствовать изменению в корпоративном долге.

Шиам-Сандер и Майерс нашли сильную поддержку своей теории на основе выборки 157 американских компаний, акции которых непрерывно обращались на организованных рынках за период 1971-1989 годов. Иерархическая теория предлагается как эмпирическая модель корпоративного левереджа. Выборка из 157 компаний является относительно небольшой по отношению к набору обращающихся акций всех американских компаний за соответствующий период. Поэтому важно понять, применима ли в данном случае иерархическая теория.

Шиам-Сандер и Майерс обратились к испытанию иерархической теории с использованием регрессионного анализа. В этом испытании попытались построить ситуацию, связанную с дефицитом финансирования из информации бухгалтерской отчетности. Финансирование дефицита построено на агрегации дивидендов, инвестиций, изменения в рабочем капитале и внутренних денежных потоках. Если иерархическая теория является корректной, то построение переменной финансирования дефицита является оправданным. Под иерархической теорией каждый компонент относительно финансирования дефицита должен иметь предсказанное влияние на корпоративный долг. Эмпирическое свидетельство не подтвердило эту гипотезу.

Иерархическая теория является конкурентом по отношению к другой эмпирической модели корпоративного левереджа. Иерархическая теория предполагает, что переменная финансирования дефицита должна превалировать над другими переменными. Если дефицит финансирования является единственным фактором среди многих, тогда реализуется обобщенная версия статической теории.

\footnotetext{
${ }^{12}$ Генеральный директор Консалтинговой компании ООО «Антарес».

Выпуск \#3(7), 2008 다의 Элекронный журнал Корпоративные Финансы, 2008
} 
Согласно иерархической теории, поведение в отношении финансирования (иерархическое использование источников финансирования: нераспределенной прибыли, выпуск новых займов или выпуск новых акций) управляет выбором затрат. Теория должна стать лучшей среди компаний, особенно связанных с серьезными проблемами неблагоприятного отбора. Небольшие компании с высоким уровнем роста представляются как компании с большими информационными асимметриями.

Иерархическая теория формирует предсказания о сроках платежа и приоритете долга в структуре капитала компании. В первую очередь компания должна эмитировать ценные бумаги с самыми низкими информационными затратами. То есть после того как исчерпаны возможности в отношении использования краткосрочного долга, компания прибегает к долгосрочной задолженности.

Генезис иерархической теории проистекает от Майерса и Мейлафа [Myers, Majluf, 1984], которые определили, что у компании есть три доступных источника финансирования: нераспределенная прибыль, долг и собственный (акционерный) капитал. Нераспределенная прибыль не имеет проблемы, связанной с неблагоприятным отбором. Собственный капитал зависим от проблемы неблагоприятного отбора, в то время как долг подвержен незначительно проблеме неблагоприятного отбора. С точки зрения внешнего инвестора собственный капитал является более рискованным, нежели долг. Оба имеют проблему неблагоприятного отбора, премию за риск, но премия за риск является большей в отношении собственного капитала. Поэтому внешний инвестор требует более высокой нормы доходности на акцию (собственный капитал), чем на долг. Образуется цепочка по вертикальному уровню финансирования: от внутреннего источника - нераспределенной прибыли, который является лучшим источником финансирования, - далее следует эмиссия долга, который является, в свою очередь, лучшим источником финансирования по отношению к собственному капиталу (эмиссия акций).

Таким образом, компания находящаяся в нормальных условиях, не будет использовать собственный (акционерный) капитал, а для целей финансирования дефицита будет произведена эмиссия долга.

Далее необходимо перейти к непосредственному описанию иерархической теории структуры капитала с использованием инструментария, предложенного Франком и Гойалом [Frank, Goyal, 2002].

При испытании иерархической теории, как правило, используется различный информационный набор, чем при обычном эмпирическом исследовании относительно левереджа и регулирования поведения левереджа.

Франк и Гойал предложили использовать регрессию левереджа и в дальнейшем использовали накопленную информацию о компаниях (исключены были финансовые учреждения и организации коммунального обслуживания) за прошлый период (1971-1993) в описании переменной дефицита финансирования для верификации самой иерархической теории.

В основе эмпирического анализа лежит регрессия левереджа, которая, в свою очередь, базируется на четырех факторах: осязаемости активов, отношении рыночной стоимости активов к балансовой стоимости, логарифме продаж и прибыльности. Основное регрессионное уравнение выглядит так:

$$
\Delta D_{i}=\alpha+\beta_{T} \Delta T_{i}+\beta_{M T B} \Delta M T B_{i}+\beta_{L S} \Delta L S_{i}+\beta_{P} \Delta P_{i}+\beta_{D E F} D E F_{i}+\varepsilon_{i},
$$

где D - уровень левереджа — определяется отношением общего долга к рыночной стоимости активов;

T - доля материальных активов в общей величине активов;

МТВ - отношение рыночной стоимости активов к их балансовой стоимости;

LS - логарифм объема продаж; 
P - прибыль, которая определяется как отношение операционной прибыли к балансовой стоимости активов;

$\mathrm{DEF}$ - финансовый дефицит определяется как разница между денежным потоком от операционной деятельности и дивидендами, уровнем долга, инвестициями, изменением в оборотном капитале;

i - временной период;

$\Delta$ - изменения между временными периодами;

$\alpha-$ свободный член уравнения регрессии $(\alpha=0)$;

$\beta$ - коэффициенты регрессии, которые определяют эмпирическое свидетельство реализации иерархической теории;

$\varepsilon$ - слагаемое ошибки.

Настоящее уравнение регрессии определяет взаимосвязь между уровнем левереджа и вышеперечисленными факторами. Для полной картины объяснения иерархической теории добавлен фактор - финансовый дефицит.

Наиболее важным из четырех факторов (прокси-переменных) является осязаемость активов. Согласно Харрису и Равиву [Harris, Raviv, 1991], в иерархической теории структуры капитала компании с небольшими материальными активами будут иметь большие проблемы, связанные с асимметричностью информации. Данные компании будут иметь тенденцию аккумулировать больше долга через какое-то время и установят более высокий уровень левереджа. Харрис и Равив утверждают, что иерархическая теория предсказывает, что $\beta_{T}<$ 0. Это является необычным предсказанием относительно роли осязаемости. Тривиальная идея основывается на гипотезе, что залоговое обеспечение поддерживает долг, и предполагается, что материальные активы служат залоговым обеспечением. Следовательно, залоговое обеспечение связано с увеличением левереджа, и, следовательно, $\beta_{T}>0$.

Компании с высокими отношениями рыночной стоимости активов к их балансовой стоимости часто думают, что имеют большие возможности для будущего роста. Гойал, Лен и Расич [Goyal, Lehn, Racic, 2002] нашли, что когда возможности роста компании снижаются, эти компании увеличивают использование долгового финансирования. Барклей, Мареллек и Смит [Barclay, Morellec, Smith, 2001] представили модель, которая показывает, что долговая способность вариантов роста может быть отрицательной и, следовательно, $\beta_{\text {мтв }}<0$.

Крупные компании являются более диверсифицированными, у них хорошая репутацию на долговых рынках, и они имеют дело с меньшими информационными затратами при заимствовании. Поэтому крупные компании имеют предсказания относительно большей величины долга в структуре капитала, и, следовательно, $\beta_{L S}>0$.

Предсказания относительно прибыльности являются неоднозначными. Статическая теория предсказывает, что прибыльные компании должны иметь более высокий уровень левереджа для возмещения корпоративных налогов. Также во многих асимметричных информационных моделях, как у Pocca [Ross, 1977], прибыльные компании имеют предсказания относительно более высокого уровня левереджа. Но Титман и Весселс [Titman, Wessels, 1988], Фама и Френч [Fama, French, 2002] показали, что это не так. Напротив, прибыль и уровень левереджа являются отрицательно коррелированными, и следовательно, $\beta_{P}<0$.

После описания уравнения регрессии уровня левереджа и определения факторов на предмет взаимодействия с уровнем левереджа необходимо перейти к исследованию иерархической теории.

Франк и Гойал [Frank, Goyal, 2002] исследовали иерархическую теорию на основе выборки 768 американских компаний (финансовые учреждения и организации коммунального обслуживания исключены) за периоды 1971-1989 и 1990-1998 годов, с использованием данных Compustat. Результаты исследования представлены в таблице 1. 
Таблица 1

Исследование иерархической теории за периоды 1971-1989 и 1990-1998 годов

\begin{tabular}{|c|c|c|}
\hline \multirow{2}{*}{ Наименование } & $\mathbf{1 9 7 1 - 1 9 8 9}$ & $\mathbf{1 9 9 0 - 1 9 9 8}$ \\
\cline { 2 - 3 } & Чистая эмиссия долга & Чистая эмиссия долга \\
\hline \multirow{2}{*}{ Constant } & 0,001 & $-0,004$ \\
& $(<0,001)$ & $(0,001)$ \\
\hline \multirow{2}{*}{ Финансовый дефицит } & 0,748 & 0,325 \\
& $(0,004)$ & $(0,004)$ \\
\hline $\mathrm{N}$ & 14,592 & 18,225 \\
\hline$R^{2}$ & 0,708 & 0,283 \\
\hline
\end{tabular}

Результаты в таблице 1 выражены чистой эмиссией долга, как зависимой переменной. За периоды 1971-1989 и 1990-1998 годов происходит значительное ослабление $R^{2}-\mathrm{c}$ 0,71 до 0,283. Данное значение определяет, что поддержка компаниями иерархической теории в 1990-х является более слабой.

Таким образом, рассмотренные выше исследования в отношении иерархической теории применимы для крупных компаний и компаний с менее серьезными проблемами, связанными с неблагоприятным отбором: выплачивающих дивиденды и с умеренным уровнем левереджа. Рассмотренные результаты позволяют сделать вывод, что иерархическая теория является более эффективной по отношению к большим компаниям.

Значение уменьшения поддержки иерархической теории объясняется отчасти тем, что пик по сделкам купли-продажи акций малых компаний пришелся на 1980-е и 1990-е годы. Даже когда на иерархической теории сосредоточено внимание крупных компаний, тем не менее через какое-то время уровень поддержки теории уменьшается. Собственный капитал становится более важным.

\section{Список литературы}

1. Barclay M.J., Morellec E., Smith C.W. On the debt capacity of growth options // Unpublished working paper. Univercity of Rochester, NY, 2001.

2. Fama E., French K. Testing tradeoff and pecking order predications about dividends and debt // Review of Financial Studies, No/ 15, 2002, p. 1-33.

3. Frank M.Z., Goyal V.K. Testing the pecking order theory of capital structure // Journal of Financial Economics, 2002.

4. Goyal V.K., Lehn K., Racic S. Growth opportunities and corporate debt policy: the case of the U.S. defense industry // Journal of Financial Economics, No. 64, April, 2002, forthcoming.

5. Harris M., Raviv A. The theory of capital structure // Journal of Finance, No. 46, 1991, p. $297-356$.

6. Myers S.C. The capital structure puzzle // Journal of Finance, No. 39, 1984, p. 575-592.

7. Myers S.C., Majluf N. Corporate financing and investment decisions when firms have information that investors do not have // Journal of Financial Economics, No. 13, 1984, p. $187-221$. 
8. Ross S. The determination of financial structure: the incentive signaling approach // The Bell Journal of Economics, No. 8, 1977, p. 23-40.

9. Shyam-Sunder L., Myers S.C. Testing static tradeoff against pecking order models of capital structure // Journal of Financial Economics No. 51, 1999, p. 219-244.

10. Titman S., Wessels R. The determinants of capital structure choice // Journal of Finance, No. 43, 1988, p. $1-21$. 